Check for updates

King's College Hospital, London, UK

Correspondence to E Rudd emilyclaire rudd@hotmail.com

Cite this as: $B M J 2021 ; 373: n 1304$

http://dx.doi.org/10.1136/bmj.n1304

Published: 7 June 2021
PRACTICE POINTER

\section{Mask related acne ("maskne”) and other facial dermatoses}

\author{
Emily Rudd, Sarah Walsh
}

What you need to know

- Not all facial dermatoses related to personal protective equipment are "maskne"

- Irritant contact dermatitis is the most common cause

- Maintenance of the skin barrier and regular "mask breaks" are important aspects of management, in addition to standard medical treatment of the skin condition

The covid-19 pandemic has led to a marked increase in the use of personal protective equipment (PPE) both in and out of healthcare settings. The term "maskne" has become increasingly popular during the pandemic, particularly in the media, where it is used to describe several facial dermatoses. Individuals often buy expensive but potentially ineffective treatments for these conditions.

In this practice pointer we summarise the most common causes of facial eruptions associated with wearing facial PPE, and highlight the key areas to cover when assessing someone with new or worsening pre-existing facial dermatoses that they attribute to the use of facial PPE.

"Facial PPE" in this article includes full face shields, visors, safety spectacles, surgical masks (fluid resistant surgical mask, FRSM type IIR), and respirator masks (eg, $\mathrm{FFP}_{3}, \mathrm{FFP} 2$, and N95). ${ }^{1}$

\section{How common is "maskne"?}

Facial dermatoses related to PPE have been well described, but data about their prevalence are limited, and often a descriptive terminology is used rather than specific diagnoses. Based on the limited available evidence, mask related acne and irritant contact dermatitis are the most common facial dermatoses associated with mask wearing. ${ }^{2-5}$

During the covid-19 pandemic, a prospective cross sectional study of 833 medical school staff in Thailand, including healthcare and non-healthcare workers, showed a self-reported prevalence of 54\% adverse skin reactions to surgical and cloth masks. ${ }^{6}$

\section{How should facial dermatoses be assessed?}

Typically, a patient presents with new onset facial eruption, or exacerbation of a pre-existing dermatosis that is most pronounced in the area covered by the mask. Ideally, such an assessment would take place in person, but video consultation provides an acceptable alternative.

\section{Key information to elicit in a "maskne" history}

- Relevant history and family history of skin disease and a comprehensive drug history that includes prescribed, over-the-counter, and complementary medicines

- Temporal relationship with mask wearing-establish if periods without mask wearing alleviate or improve the problem, eg, allergic contact dermatitis should improve with a period of no mask wearing, while acne, once established, may not respond so readily

- Symptoms of itch, soreness, and appearance of pustules or papules

- Duration of PPE exposure each day

- Ask if "mask breaks" (periods of time when facial PPE is removed entirely) are allowed or taken

- Assess the impact on the patient's mood, work, and social life to assess severity and decide further management. The effect of PPE related dermatoses on the life quality of healthcare workers can be substantial ${ }^{3}$

Examination should focus on the morphology of the eruption, the distribution, and whether it is present at sites other than the face.

\section{What are the common causes and how should they be treated?}

Each condition described below may appear de novo or be exacerbated by wearing facial PPE. Exacerbation tends to result from the development of a warm, moist, occlusive environment around the face, particularly during mask use. Added to this is the frictional effect of the material held in place with elastic.

General measures to prevent PPE related facial dermatoses are outlined in the box and are advised in the treatment of all conditions listed below. Additional standard medical treatment for each dermatosis is discussed separately. When post-inflammatory hyperpigmentation or scarring occurs, a more aggressive treatment approach is required to prevent irreversible skin changes. Referral to specialist care is warranted at this stage if no improvement occurs.

\section{Irritant contact dermatitis}

Irritant contact dermatitis (ICD) is the most common occupational and mask related dermatosis. ${ }^{3}$ ICD is a form of exogenous eczema caused by direct physical or chemical injury. Pressure ICD related to facial masks is commonly described ${ }^{4}$ over the cheeks and nasal bridge. ${ }^{35}$ It is associated with prolonged mask wearing ( $>6$ hours) and its severity depends on the irritant and chronicity of exposure. ${ }^{3}$ Presentation ranges from a discrete, dry, scaly patch to oedema and vesicles, erosions, and ulceration. ${ }^{35}$ People with 
atopic dermatitis, who already have a defective skin barrier, are particularly at risk of developing ICD. ${ }^{7}$

Enabling restoration of the skin barrier is key to treating ICD, and regular mask breaks (every hour for respirators) is one way to do this. ${ }^{8}$ For broken skin, a silicon backed dressing such as Mepilex Border Lite can be applied to protect the skin and ensures that the mask seal remains intact. ${ }^{9}$

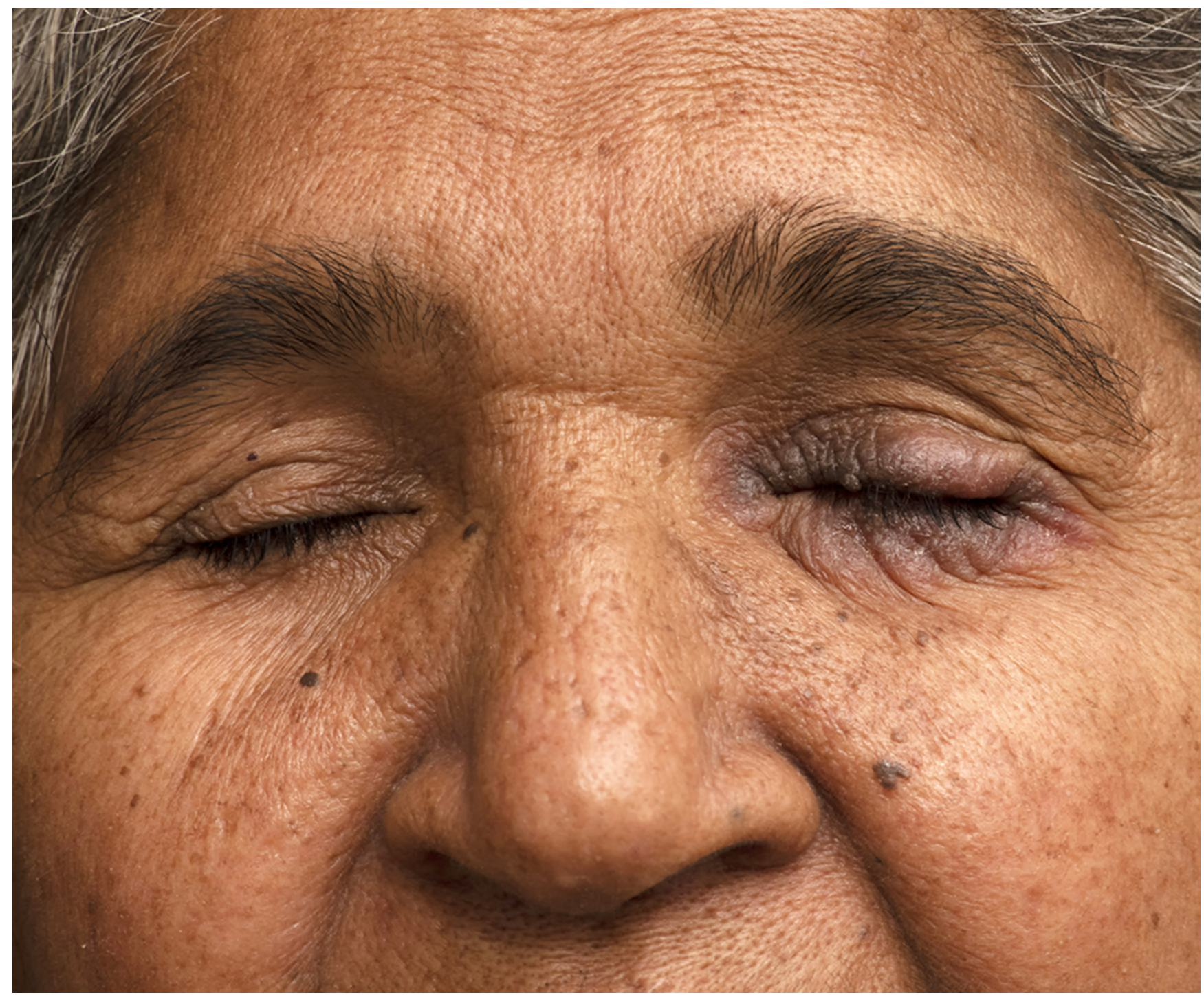

Fig 1 | Allergic contact dermatitis

ICD and ACD can be clinically indistinguishable. Both usually manifest as localised dermatitis but well demarcated areas of inflammation and redness are more suggestive of ACD, while a more diffuse pattern is more commonly seen in ICD. Treatment involves a short course of a mild to moderate potency corticosteroid, such as hydrocortisone $1 \%$ ointment. Avoiding allergens prevents further episodes, and therefore identification of causative agents is key. This can be achieved by patch testing, indicated where well demarcated areas are seen clinically and in cases of severe disease.

\section{Allergic contact dermatitis}

Allergic contact dermatitis (ACD) (fig 1) is a delayed type IV hypersensitivity reaction to an external allergen, and is much less common than ICD. ${ }^{910}$ Typically, it occurs after exposure to preservatives such as formaldehyde ${ }^{11}$ and dibromodicyanobutane, ${ }^{12}$ but thiuram, a rubber accelerator found in the elastic straps on surgical masks, ${ }^{13}$ is also a recognised allergen. Metal wires are used to mould the mask to the face; nickel and cobalt have both been reported as causes of facial ACD. ${ }^{14}$ facial skin of a patient with eczema, plus the occlusive, moist environment favoured by mask wearing may have a deleterious effect on the skin, favouring the worsening of eczema.

\section{Atopic eczema}

Atopic eczema is a very common dermatitis that affects up to $20-30 \%$ of children and $2-10 \%$ of adults. ${ }^{15}$

Wearing a mask may have an irritant effect on the more delicate 


\section{Seborrhoeic eczema}

This dermatosis (fig 2) affects approximately 1-3\% of the adult population and usually starts in young adult life. ${ }^{16}$ On examination, a dermatitis with greasy yellow scale predominantly affecting the scalp, eyebrows, glabellar, and nasolabial folds is common.
Management involves regular antifungals such as ketoconazole $2 \%$ shampoo and/or short courses of mild topical corticosteroids such as hydrocortisone $1 \%$ ointment. ${ }^{17}$ As with atopic eczema, the warm, moist, occlusive environment created by mask wearing may predispose to development of seborrhoeic dermatitis.

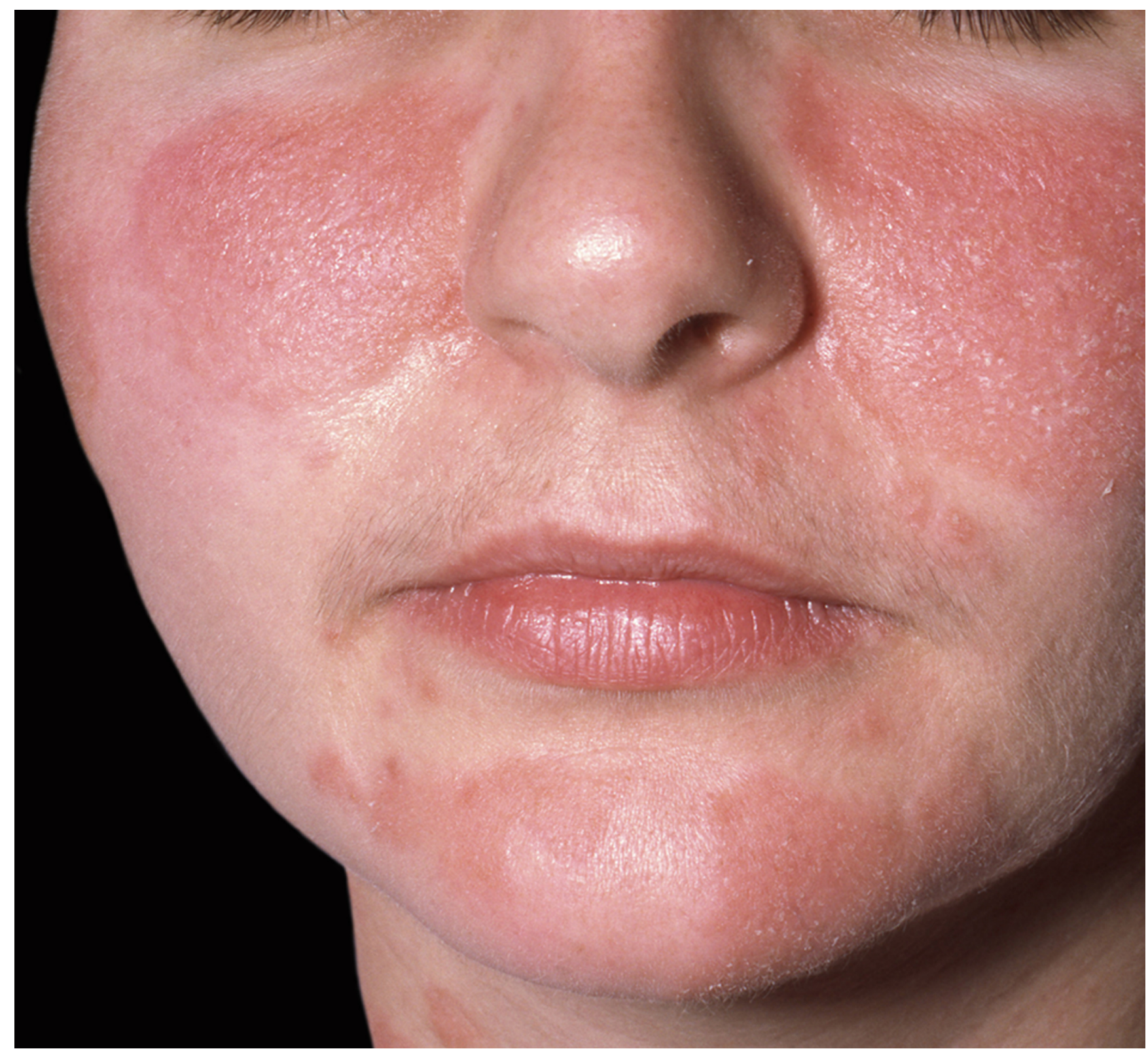

Fig 2 | Seborrhoeic eczema

\section{Periorificial dermatitis}

Periorificial dermatitis consists of a patchy erythema with tiny papulopustules, affecting the periocular and perioral skin of young women (with sparing of the vermilion border). It can be idiopathic, or is caused by the use of cosmetics or topical corticosteroids directly or indirectly (via fingers that are applying the agent elsewhere). Mask wearing may predispose to the development of periorificial dermatitis for reasons similar to those listed for atopic and seborrhoeic dermatitis. Management involves stopping the implicated cream and simplifying the skin care regimen. Topical antibiotics such as erythromycin will suffice for milder cases but often a four week course of a tetracycline, such as lymecycline 408 mg once daily, is needed. ${ }^{18}$

\section{Urticaria}

Both pressure and contact urticaria (fig 3 ) are uncommon complications of PPE. ${ }^{11} 19$ Pressure urticaria is caused by the downward pressure of the mask and is characterised by the formation of wheals, immediately or delayed (4-6 hours), after a pressure stimulus. A well fitted mask that is not over tight is recommended, or alternatively a change in PPE. ${ }^{19}$ 


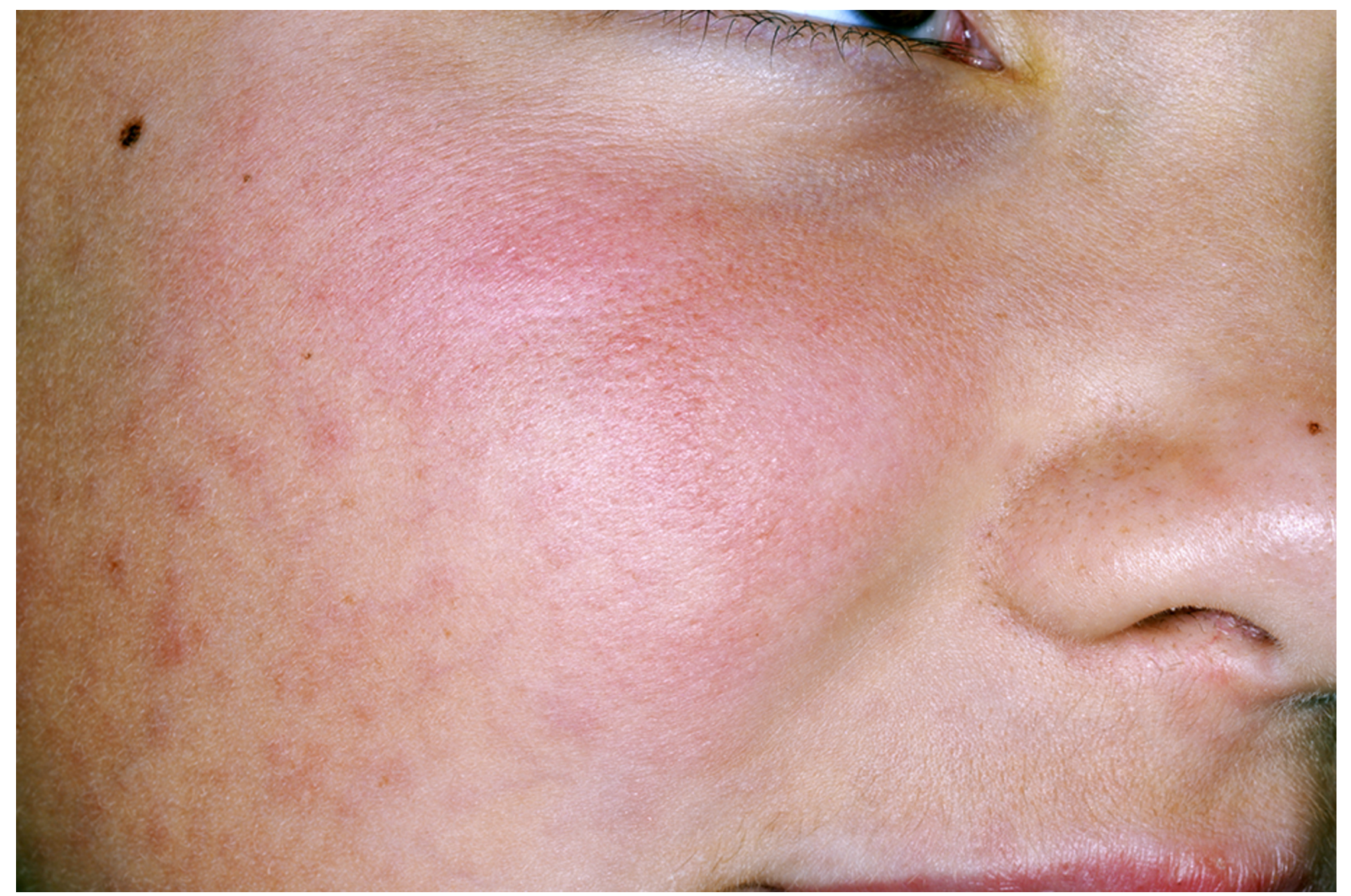

Fig 3 | Urticaria

Contact urticaria is an immediate reaction to an offending allergen such as latex or formaldehyde. It typically resolves within 24 hours of removal of the contact trigger. Regular non-sedating $\mathrm{H} 1$ antihistamines such as loratadine are the mainstay of treatment for inducible urticaria. ${ }^{20}$

\section{Acne}

Acne vulgaris (fig 4) is a chronic inflammatory disease of the pilosebaceous unit. PPE related acne, which may be considered a subtype of acne mechanica, occurs in people with a previous history of acne vulgaris as well as in those previously unaffected. It has been associated with surgical masks and N95 respirators. ${ }^{23} 21$ 


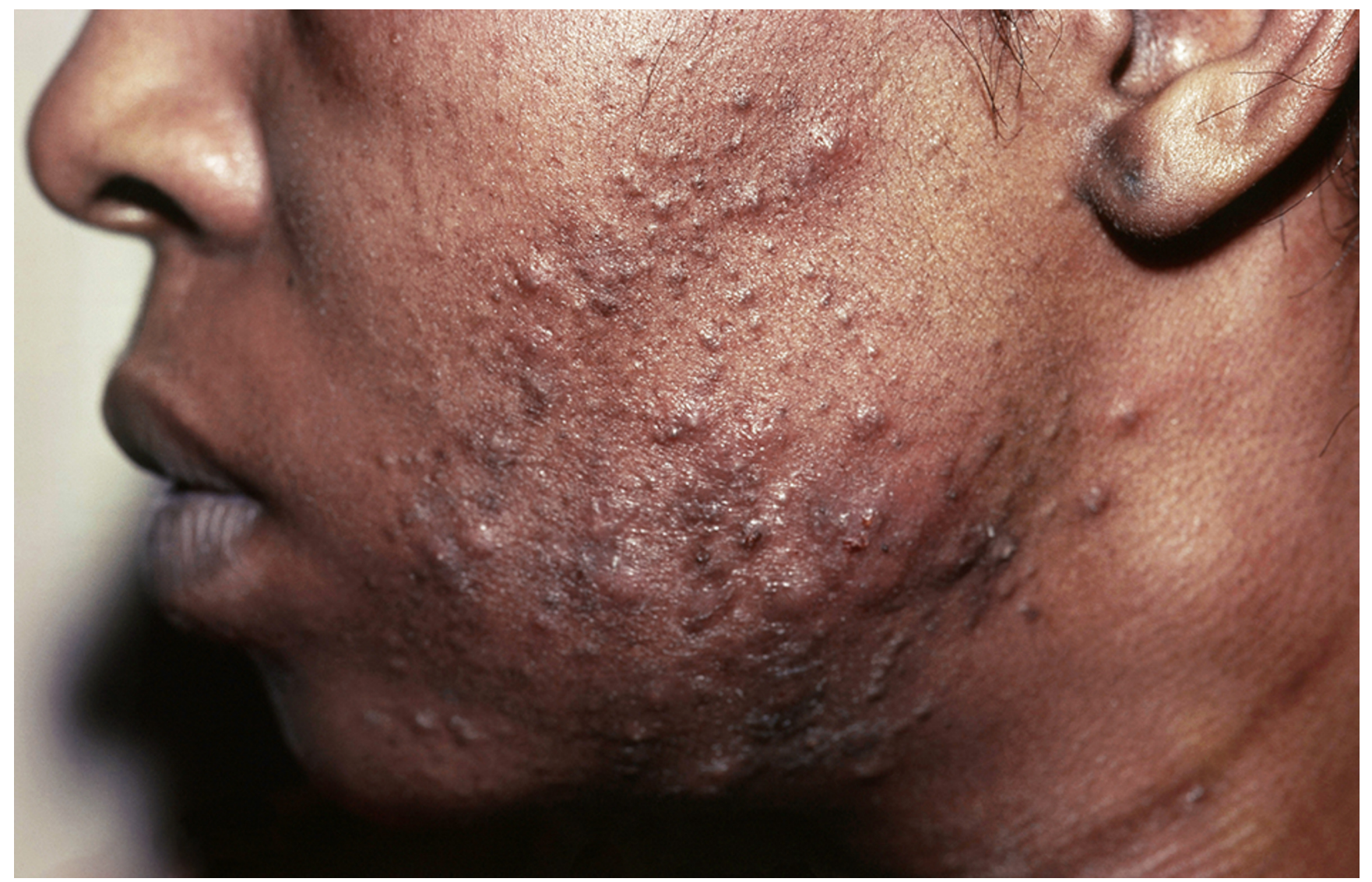

Fig 4 | Acne

The pathogenesis of PPE related acne is thought to be threefold:

- Creation of a humid microclimate inside the mask

- Mucosa can be colonised by bacteria which could increase bacterial load on the surrounding skin

- Friction effect of a close fitting mask can damage the follicular ostia causing chronic irritation, and this effect is worsened by heat and humidity. ${ }^{22}$

Retinoids such as adapalene cream alone or in combination with benzoyl peroxide cream once daily can be used for mild cases, with the addition of an oral tetracycline such as lymecycline $408 \mathrm{mg}$ once daily for up to 12 weeks for moderate to severe cases. ${ }^{23}$

\section{Rosacea}

Rosacea (fig 5) typically affects adults aged 30-50 with fair skin. ${ }^{18}$ Commonly, patients present with facial erythema and telangiectasias of the convexities (chin, cheeks, nose, forehead). The classic area of distribution of rosacea overlaps with that covered by a mask when worn correctly. The chronicity and presence of telangiectasias usually help to distinguish rosacea from peri-orifical dermatitis. Rosacea can be induced or worsened by prolonged periods of mask wearing. Medical treatment includes topical agents such as ivermectin $1 \%$ cream once daily for mild cases. An oral tetracycline such as moderate release doxycycline $40 \mathrm{mg}$ once daily for 8-12 weeks can be added for moderate to severe cases. ${ }^{24}$ 


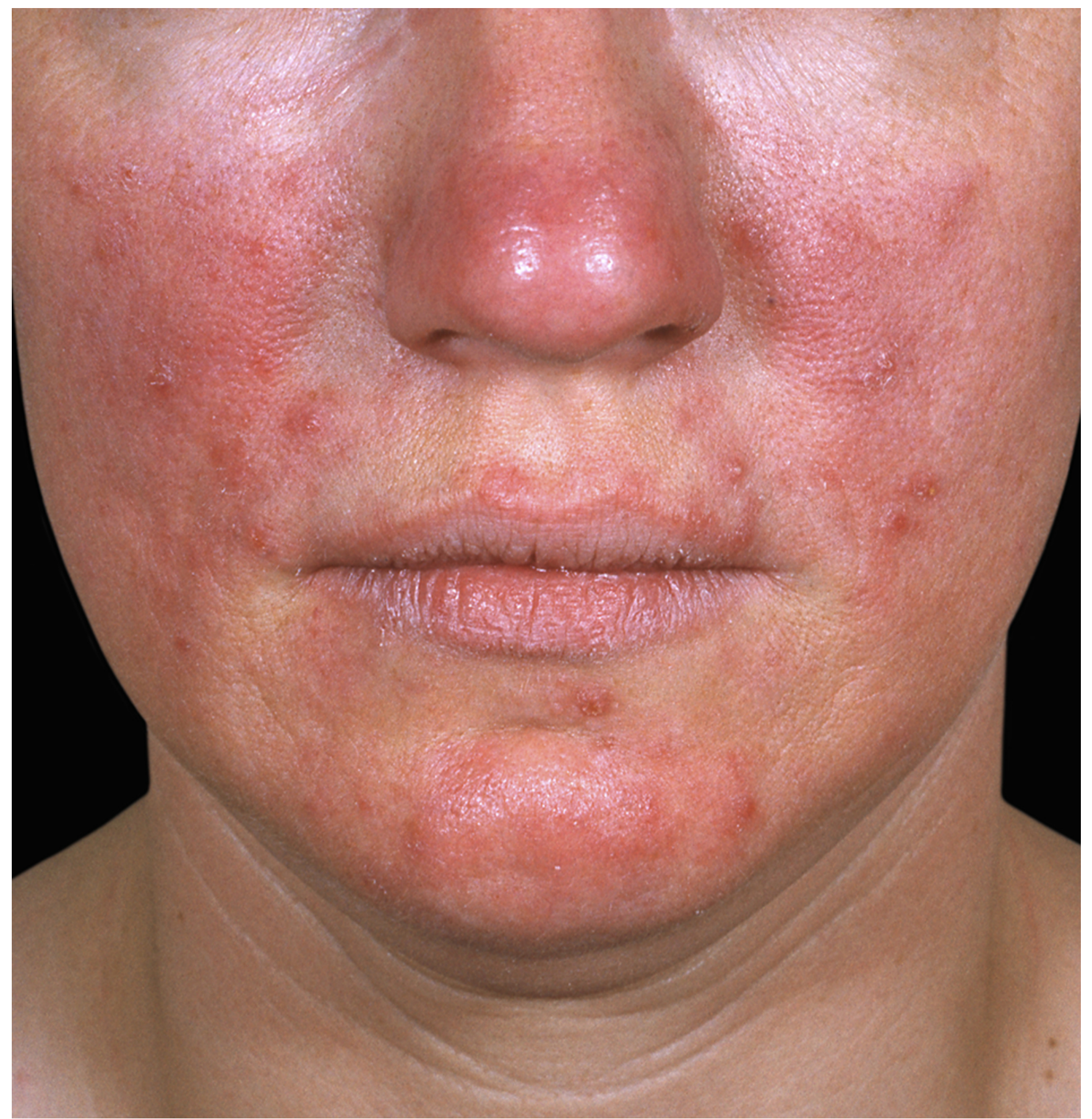

Fig 5 | Rosacea

\section{Folliculitis}

Folliculitis (fig 6) on the face is more common in men because of its association with facial hair. Occlusive folliculitis, bacterial folliculitis, and pseudofolliculitis barbae (caused by ingrowing hairs) have clinically similar presentations with papules, pustules, and more rarely nodules. A swab can exclude bacterial infection. Gentle daily cleansing with a soap-free cleanser, gentle exfoliation (to release ingrown hairs), and replacing dry shaving with wet shaving can all be helpful. Antibiotic treatment is indicated where bacteria are isolated; in purely inflammatory (sterile) cases, a combination steroid/antimicrobial cream can be used. ${ }^{25}$ 


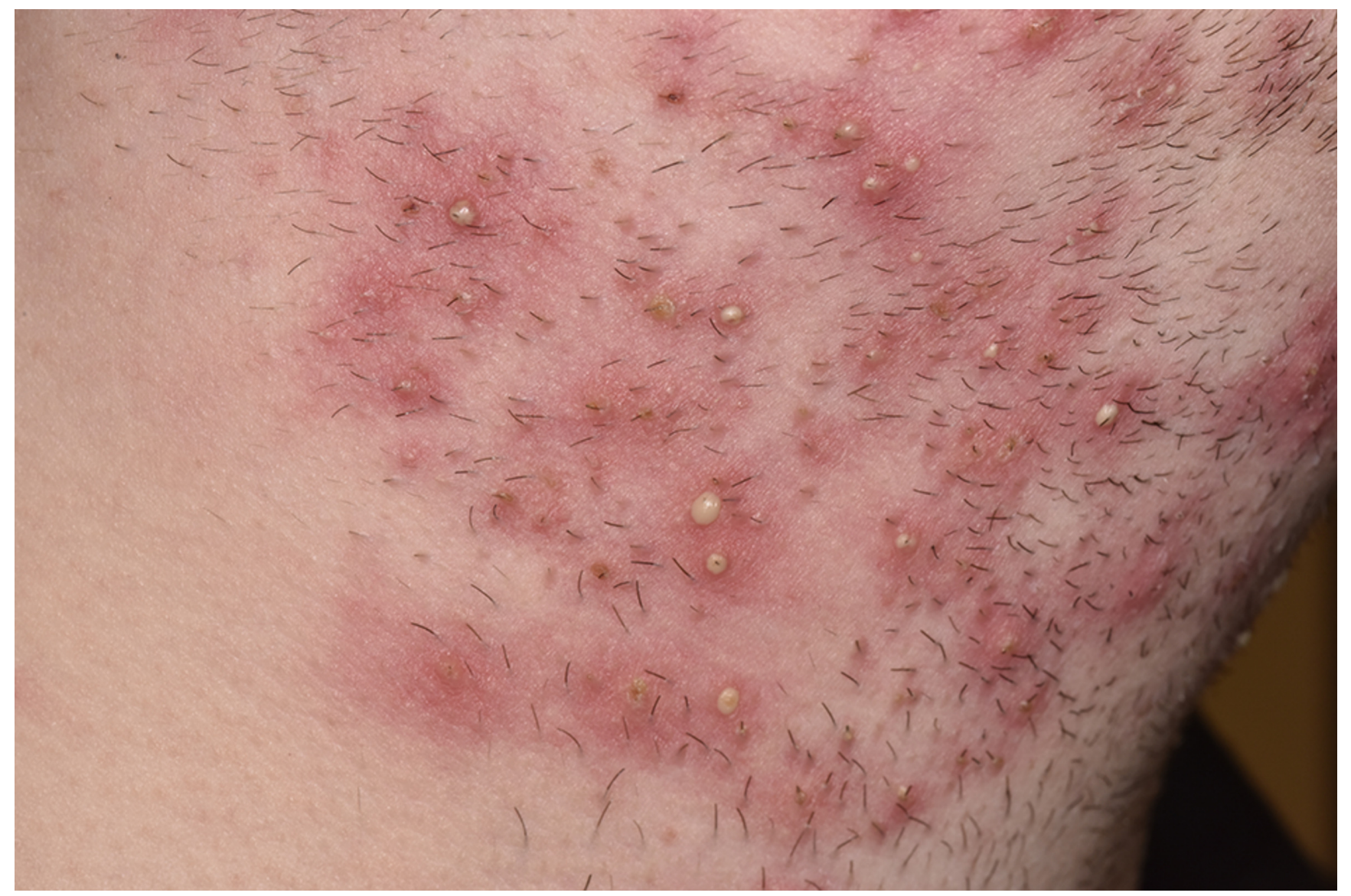

Fig 6 | Folliculitis

\section{General measures to prevent PPE related facial dermatoses ${ }^{26}$}

- Cleanse $\operatorname{skin}^{26}$ with a gentle soap-free cleanser

- Apply a light emollient at least 30 minutes before applying facial PPE $^{26}$

- Apply a silicon based barrier tape-eg, siltape (Advancis)-to nasal bridge and cheeks 49

- Wipe skin under PPE with a silicon based barrier wipe to provide a film, protecting the skin from the harmful microenvironment ${ }^{26}$

- Take time to fit the mask and ensure it is not over tight ${ }^{26}$

- Take regular breaks from the mask (every one hour for respirators) to relieve the pressure and prevent moisture build up ${ }^{26}$
- Stay well hydrated ${ }^{26}$

- Maintain oral hygiene (teeth brushing twice daily and daily interdental flossing/brushing) ${ }^{27}$

\section{When to refer}

Consider referral to secondary care in cases of severe, debilitating disease, or if the condition fails to respond to the treatments described above. Also consider a routine referral if specialist investigations, such as skin prick testing and patch testing in cases of suspected contact allergy, are indicated. 


\section{thebmj Visual summary 0 Facial distribution of "maskne"}

Assessing dermatoses after extended use of facial personal protective equipment

The covid-19 (SARS-CoV-2) pandemic has increased the use of personal protective equipment (PPE) such as face shields, visors, safety spectacles, and surgical masks. The term "maskne" may describe a myriad of facial dermatoses associated with wearing masks and other PPE. A key element of understanding the possible causes of these dermatoses is to consider the facial distribution and involvement of extra-facial sites. This graphic presents common distributions that can be used as a starting point for assessment of facial eruptions that may be caused by use of PPE.

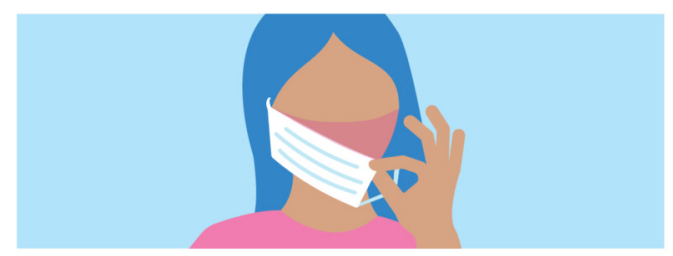

\section{Facial distribution}

Extra-facial involvement

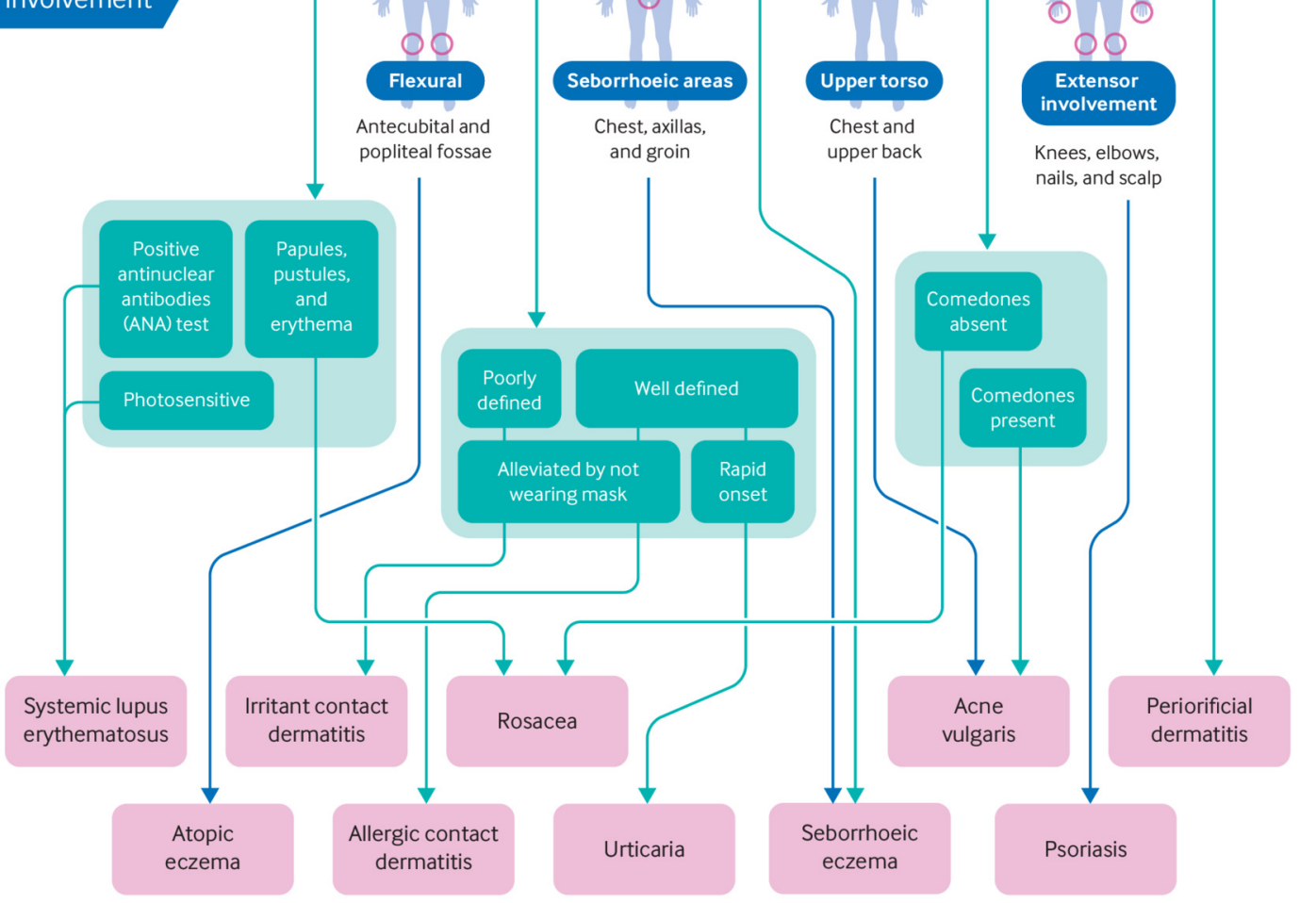

\section{thebmi Read the full https://bit.ly/BMJmaskne2}
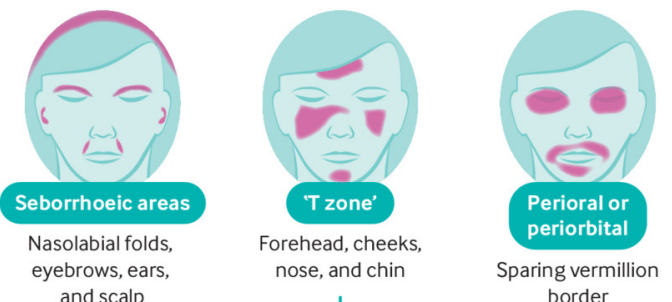

border

\section{Education into practice}

- Consider how a facial dermatosis affects the patient's quality of life, work, and relationships
- Reflect on whether you incorporate considerations of different Fitzpatrick skin types in your treatment decisions, given the higher risk of post-inflammatory dyspigmentation and/or scarring in darker skin types 
- Consider the occupational implications of the diagnosis and treatment for the patient, and discuss these as part of the consultation

- Signpost patients to the British Association of Dermatologists website as a useful repository of good quality reliable patient information leaflets on skin conditions (https://www.bad.org.uk)

\section{How patients were involved in the creation of this article}

This article was reviewed by two healthcare workers who had experienced PPE related facial dermatoses and whose experience of receiving care informed the content of this article. Specifically, they advised on the content of the box "General measures to prevent PPE related facial dermatoses."

\section{How this article was made}

We obtained evidence using a systematic search of Medline, Embase, and Pubmed. Searches were confined to those publications written in the English language. Search terms used were "facial dermatoses" and "mask," "facial dermatoses" and "PPE," "acne" and "PPE," "acne" and "mask," "eczema" and "mask," "allergic contact dermatitis" and "mask," "FFP3 mask" and "skin," "N95 mask" and "skin."

Competing interests: We have read and understood the $B M$ p policy on declaration of interests and have none to declare.

Provenance and peer review: Commissioned; externally peer reviewed

$1 \quad$ BMJ visual summary. Covid-19 PPE guidance. 2020. https://www.bmj.com/sites/default/files/attachments/resources/2020/04/cv19-ppe-v1.0-web.pdf.

2 Foo CCI, Goon ATJ, Leow Y-H, Goh C-L. Adverse skin reactions to personal protective equipment against severe acute respiratory syndrome--a descriptive study in Singapore. Contact Dermatitis 2006;55:291-4. doi: 10.1111/j.1600-0536.2006.00953.x pmid: 17026695

$3 \mathrm{Yu}$ J, Chen JK, Mowad CM, etal. Occupational dermatitis to facial personal protective equipment in health care workers: A systematic review. J Am Acad Dermatol 2021;84:486-94. doi: 10.1016/j.jaad.2020.09.074 pmid: 33011325

4 Ferguson F], Street G, Cunningham L, White IR, McFadden JP, Williams I. Occupational dermatology in the time of the COVID-19 pandemic: a report of experience from London and Manchester, UK. Br J Dermatol 2021;184:180-2. doi: 10.1111/bjd.19482 pmid: 32790187

5 Lan J, Song Z, Miao X, etal. Skin damage among health care workers managing coronavirus disease-2019. J Am Acad Dermatol 2020;82:1215-6.

doi: 10.1016/j.jaad.2020.03.014 pmid: 32171808

6 Techasatian L, Lebsing S, Uppala R, etal. The effects of the face mask on the skin underneath: A prospective survey during the covid-19 pandemic. J Prim Care Community Health 2020;11:2150132720966167. doi: 10.1177/2150132720966167 pmid: 33084483

7 Visser MJ, Landeck L, Campbell LE, etal. Impact of atopic dermatitis and loss-of-function mutations in the filaggrin gene on the development of occupational irritant contact dermatitis. Br J Dermatol 2013;168:326-32. doi: 10.1111/bjd.12083 pmid: 23039796

8 Buckley D, Stone NBritish Society for Cutaneous Allergy Committee. British Society for Cutaneous Allergy advice on skin damage from FFP3 masks. BM/2020;369:m2268. doi: 10.1136/bmj.m2268. pmid: 32518080

9 Payne A. Covid-19: skin damage with prolonged wear of FFP3 masks. BMJ 2020;369:m1743. doi: 10.1136/bmj.m1743 pmid: 32366499

10 Sasseville D. Occupational contact dermatitis. Allergy Asthma Clin Immunol 2008;4:59-65. doi: 10.1186/1710-1492-4-2-59 pmid: 20525126

11 Donovan J, Kudla I, Holness LD, etal. Skin reactions following use of N95 facial masks. Dermatitis 2007;18:104doi: 10.1097/01206501-200706000-00013

12 Al Badri FM. Surgical mask contact dermatitis and epidemiology of contact dermatitis in healthcare workers. Curr Allergy Clin Immunol 2017;30:183-8.

13 Kosann MK, Brancaccio R, Cohen D. Occupational allergic contact dermatitis in an obstetrics and gynecology resident. Am J Contact Dermat 2003;14:217-8. doi: 10.1097/01634989-200312000-00009 pmid: 14738725

14 Warshaw EM, Schlarbaum JP, Silverberg II, etal. Safety equipment: When protection becomes a problem. Contact Dermatitis 2019;81:130-2. doi: 10.1111/cod.13254 pmid: 30809819

15 McAleer MA, O'Regan GM, Irvine AD. Atopic dermatitis. In Bolognia JL, Schaffer JV, Cerroni L, eds. Dermatology. 4th ed. Elsevier, 2018 208-27.

16 Wakelin S. Seborrhoeic dermatitis. In Griffiths C, Barker J. Bleiker T, Chalmers R, Creamer D. Rook's Textbook of Dermatology. 9th ed. John Wiley \& Sons, 2016.

17 National Institute for Health and Care Excellence. Seborrhoeic dermatitis face and body. 2019. https://cks.nice.org.uk/topics/seborrhoeic-dermatitis/management/seborrhoeic-dermatitis-facebody/
18 Powell FC. Rosacea. Griffiths C, Barker J, Bleiker T, Chalmers R, Creamer D eds. Rook's Textbook of Dermatology. 9th ed. John Wiley \& Sons, 2016.

19 Yan Y, Chen H, Chen L, etal. Consensus of Chinese experts on protection of skin and mucous membrane barrier for health-care workers fighting against coronavirus disease 2019. Dermatol Ther 2020:33:e13310. doi: 10.1111/dth.13310. pmid: 32170800

20 Grattan CEH, Humphreys FBritish Association of Dermatologists Therapy Guidelines and Audit Subcommittee. Guidelines for evaluation and management of urticaria in adults and children. $B$ J Dermatol 2007;157:1116-23. doi: 10.1111/j.1365-2133.2007.08283.x pmid: 18021095

21 O'Neill H, Narang I, Buckley DA, etal. Occupational dermatoses during the COVID-19 pandemic a multicentre audit in the UK and Ireland BJD, 2020. doi: 10.1111/bjd.19632.

22 Draelos ZD. Acne mechanica. Zeichner JA. Acneiform eruptions in dermatology. A differential diagnosis. Springer, 2014.

23 National Institute for Health and Care Excellence. Acne vulgaris. 2020 https://cks.nice.org.uk/topics/acne-vulgaris/.

24 National Institute for Health and Care Excellence. Rosacea. 2021. https://cks.nice.org.uk/topics/rosacea/management/rosacea/.

25 Hay R, Morris-Jones R, Jemec GBE. Other acquired disorders of the pilosebaceous unit. In Griffiths C, Barker J, Bleiker T, Chalmers R, Creamer D. Rook's Textbook of Dermatology. 9th ed. John Wiley \& Sons, 2016

26 NHS England, NHS Improvement. Helping prevent facial skin damage beneath tight fitting face piece respirators (FFP2 and 3 masks) version 4. 2020. https://www.england. nhs.uk/coronavirus/wp-content/uploads/sites/52/2020/03/C0129_Preventing_skin_damage_under_PPE_V6_29.10.20.pdf.

27 Macklis P, Adams K, Kaffenberger J, Kumar P, Krispinsky A, Kaffenberger B. The association between oral health and skin disease I Clin Aesthet Dermato $2020 \cdot 13 \cdot 48-53$ pmid: 32884621 